\title{
CHF Enhancement of Advanced 37-Element Fuel Bundles
}

\author{
Joo Hwan Park, Jong Yoeb Jung, and Eun Hyun Ryu \\ Korea Atomic Energy Research Institute, 989-111 Daedukdaero, Yuseong-gu, Taejon 305-353, Republic of Korea \\ Correspondence should be addressed to Joo Hwan Park; jhpark@kaeri.re.kr
}

Received 28 October 2014; Accepted 30 January 2015

Academic Editor: Antonio Carlos Marques Alvim

Copyright (c) 2015 Joo Hwan Park et al. This is an open access article distributed under the Creative Commons Attribution License, which permits unrestricted use, distribution, and reproduction in any medium, provided the original work is properly cited.

A standard 37-element fuel bundle (37S fuel bundle) has been used in commercial CANDU reactors for over 40 years as a reference fuel bundle. Most CHF of a 37S fuel bundle have occurred at the elements arranged in the inner pitch circle for high flows and at the elements arranged in the outer pitch circle for low flows. It should be noted that a $37 \mathrm{~S}$ fuel bundle has a relatively small flow area and high flow resistance at the peripheral subchannels of its center element compared to the other subchannels. The configuration of a fuel bundle is one of the important factors affecting the local CHF occurrence. Considering the CHF characteristics of a 37S fuel bundle in terms of CHF enhancement, there can be two approaches to enlarge the flow areas of the peripheral subchannels of a center element in order to enhance CHF of a $37 \mathrm{~S}$ fuel bundle. To increase the center subchannel areas, one approach is the reduction of the diameter of a center element, and the other is an increase of the inner pitch circle. The former can increase the total flow area of a fuel bundle and redistributes the power density of all fuel elements as well as the CHF. On the other hand, the latter can reduce the gap between the elements located in the middle and inner pitch circles owing to the increasing inner pitch circle. This can also affect the enthalpy redistribution of the fuel bundle and finally enhance CHF or dry-out power. In this study, the above two approaches, which are proposed to enlarge the flow areas of the center subchannels, were considered to investigate the impact of the flow area changes of the center subchannels on the CHF enhancement as well as the thermal characteristics by applying a subchannel analysis method.

\section{Introduction}

Wolsong unit 1, which is one of four CANDU units at the Wolsong site in Korea, was recently shut down after reaching the end of its 30-year life time. It had been refurbished during the last several years. One of the main refurbished components was the aged pressure tube, which was expanded diametrically as well as axially owing to irradiation damage over a long period of time. It is known that the diametrical expansion of the pressure tube can deteriorate the CHF performance and finally reduce the thermal margin or operating power. There have been many studies on enhancing the CHF and/or critical channel power (CCP), which is determined by the dry-out and hydraulic characteristic curves of the primary heat transfer system of a CANDU reactor. In the late 1970s, a turbulent promoter was invented to increase the turbulent intensity surrounding the fuel elements in a fuel channel [1]. The axial position or the number of bearing pad planes was changed, or the number of spacer pad planes was increased to enhance the CHF by means of increasing the turbulent intensity or flow mixing within a fuel passage [2]. These attempts provided a CHF increase, but an adverse effect on the CCP existed to worsen the hydraulic characteristics of the primary heat transfer system when increasing the pressure drop of the fuel channel [3].

Recently, one of the studies to enhance the CHF was the development of the CANFLEX fuel bundle, which is composed of two element sizes and attaches the CHF enhancement buttons to 43-element fuels [4]. It is known that the CANFLEX fuel bundle achieves a remarkable CHF enhancement by attaching a special appendage called a CHF enhancement button on the fuel element [5]. However, it has not been commercialized yet owing to a more complex design and higher fabrication cost potentially than those of a $37 \mathrm{~S}$ fuel bundle.

In particular, a $37 \mathrm{~S}$ fuel bundle has 37 fuel elements which are arranged circularly. It contains four pitch circles, that is, center, inner, middle, and outer pitch circles, to properly configure the circular bundle structure. From the previous CHF experiments, most $\mathrm{CHF}$ of a $37 \mathrm{~S}$ fuel bundle have 
occurred at the elements arranged in an inner pitch circle at high flows [6] or under reactor conditions of which the reference flow rate is $24 \mathrm{~kg} / \mathrm{s}$ [7]. It should be noted that a $37 \mathrm{~S}$ fuel bundle has a relatively small flow area and high flow resistance at the peripheral subchannels of the center element compared to the other subchannels. The configuration of a fuel bundle is one of the important factors affecting the local CHF occurrence. The diameter effect of the fuel elements arranged in the center, inner, middle, and outer pitch circles of a $37 \mathrm{~S}$ fuel bundle has recently been studied [8]. It was shown that the dry-out power of a fuel bundle has a tendency to increase as the element diameter decreases within the size limitation.

Considering the $\mathrm{CHF}$ characteristics of a $37 \mathrm{~S}$ fuel bundle in terms of CHF enhancement, there can be two approaches to enlarge the flow areas of the peripheral subchannels of a center element in order to enhance the CHF of a $37 \mathrm{~S}$ fuel bundle. To increase of the center subchannel areas, one approach is the reduction of the diameter of a center element and another is the increase of the inner pitch circle.

The former can increase the total flow area as well as the center subchannel area of a fuel bundle. Additionally, the power densities of the other 36 fuel elements can be increased to compensate for the power density reduction of a small center element. It was noted that a $37 \mathrm{~S}$ fuel bundle with a small center element can enhance the CHF and finally improve the thermal margin of a CANDU fuel bundle. However, it can redistribute the power density of the remaining 36 fuel elements and increase the maximum fuel temperature of the hottest elements arranged in the outer pitch circle. Moreover, it may deteriorate the safety margin related to the coolant void reactivity by increasing the coolant volume in the fuel channel.

On the other hand, the latter can also increase the flow area of the peripheral subchannels of a center element without any change in the total flow area or bundle configuration. However, it can reduce the gap between the elements arranged in the middle and inner pitch circle owing to an increase in the inner pitch circle. This can affect the enthalpy redistribution of the fuel bundle as well as the radial $\mathrm{CHF}$ locations and dry-out power. Finally, it can enhance the CHF without any impact on the safety margin and fuel fabrication cost.

In this study, the above two approaches which were proposed to enlarge the flow areas of the center subchannels were examined in terms of the CHF or dry-out power enhancement by using the subchannel analysis code, ASSERT [9]. In addition, the thermal characteristics of two kinds of modifications were compared to those of a $37 \mathrm{~S}$ fuel bundle.

\section{Subchannel Modelling}

A 37-element fuel bundle is composed of 37 fuel elements and two types of appendages such as spacers and bearing pads. Those appendages are welded onto the surface of the fuel elements to maintain the gap among fuel elements and between the fuel bundle and pressure tube, respectively. In addition, two end plates were welded at both ends of 37

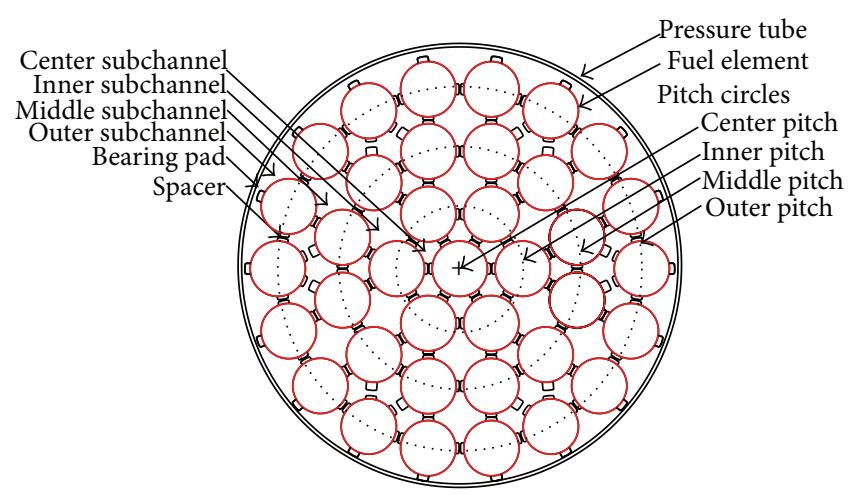

FIGURE 1: Cross-sectional view of a $37 \mathrm{~S}$ fuel bundle.

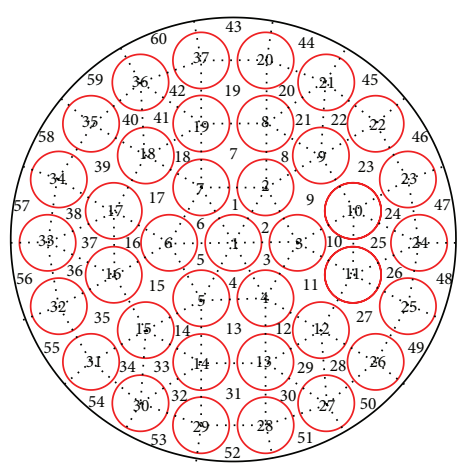

FIGURE 2: Rod and subchannel numbers of a $37 \mathrm{~S}$ fuel bundle.

fuel elements to configure a bundle structure. Twelve fuel bundles are loaded horizontally into a horizontal pressure tube. Figure 1 shows the cross-sectional view of a $37 \mathrm{~S}$ fuel bundle located in a pressure tube. When the coolant flows into the fuel channel, the channel flow can be distributed into the open spaces among the fuel elements and pressure tube depending on the flow resistance of the subchannels, which are divided by the hypothetical line connected between the centers of the fuel elements, as shown in Figure 1. The number of total fuel elements and subchannels is 37 and 60 , respectively, as shown in Figure 2. When the subchannel analysis is being performed, the minimum symmetric angle should be 180 degrees because a fuel bundle can be laid down at the bottom inside of a horizontal pressure tube. However, the present subchannel modeling of a 37-element fuel bundle selects a full bundle configuration, not considering a symmetric angle.

2.1. Area of Center Subchannels. A $37 \mathrm{~S}$ fuel bundle is composed of four pitch circles, that is, the center, inner, intermediate, and outer circles. The center subchannels are composed of subchannel numbers 1 through 6 , the inner subchannels are composed of subchannel numbers 7 through 18, the middle subchannels are composed of subchannel numbers 19 through 42, and the outer subchannels are composed of subchannel numbers 43 through 60, as shown in Figure 2. To increase the flow area of the center subchannels, there may be two approaches: one is the modification of the inner pitch 
TABLE 1: Geometries of the modifications of standard 37-element fuel.

\begin{tabular}{lccccc}
\hline \multirow{2}{*}{ Pitch circle identification } & \multicolumn{2}{c}{ Pitch circle radius, mm } & \multicolumn{2}{c}{ Element diameter } & \multirow{2}{*}{ Number of elements } \\
& 37S fuel & Mod. pitch & 37S fuel & Mod. diam. & 13.08 \\
Center & 0 & 0 & 13.08 & 13.08 & 1 \\
Inner & 14.88 & $14.88 \sim 15.38$ & 13.08 & 13.08 & 12 \\
Middle & 28.75 & 28.75 & 13.08 & 13.08 & 18 \\
Outer & 43.33 & 43.33 & & & \\
\hline
\end{tabular}

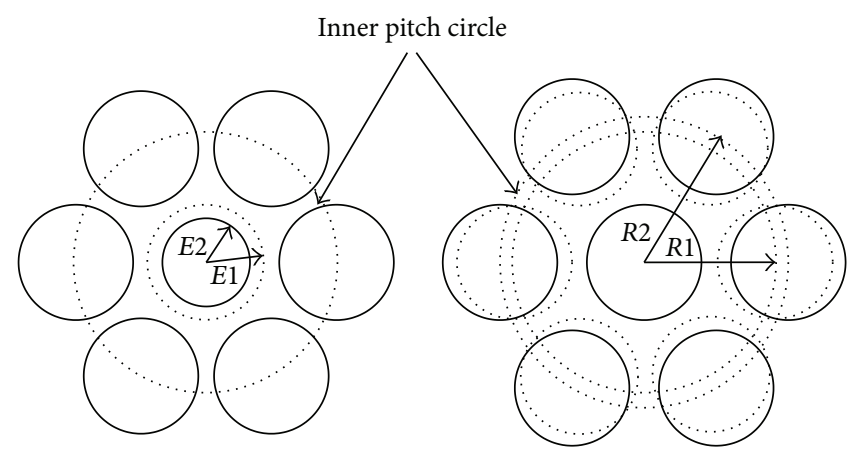

(a) Modification of center pin

(b) Modification of pitch circle

FIGURE 3: Schematic views of increasing the flow area of the center subchannels.

circle and the other is a modification of the diameter of the center element discussed in the previous section. When an inner pitch circle is increased, the flow areas of the center subchannels can be increased while the gap between the inner 6 elements and middle 12 elements should be reduced, as shown in Figures 2 and 3.

In the case of the diameter decrease of a center element, however, the total flow area and element power densities of the remaining 36 elements should be increased, if even slightly. This may affect the fuel safety, such as on the void reactivity and the maximum fuel temperature, as well as fuel management costs. These modifications can affect the subchannel flow and enthalpy distributions and finally change the CHF location and dry-out power. The geometries of both types of modifications are summarized in Table 1.

The lengths of the inner pitch circle can be increased up to $15.38 \mathrm{~mm}$, considering the minimum gap interference between the inner 6 elements and middle 12 elements, as studied in [10]. On the other hand, for the element diameter modification, the diameter of a center element was selected as $11.5 \mathrm{~mm}$, which was already used for the development of a $37 \mathrm{M}$ fuel bundle [11]. The flow area variation of the center subchannels and total subchannels for the inner pitch modification were plotted and compared to that of the modification of a center element, as shown in Figure 4.

For the present calculation, the length of the inner pitch for the pitch circle modification was selected as $15.28 \mathrm{~mm}$, which gave almost the same flow area of the center subchannel as that of a center element diameter of $11.5 \mathrm{~mm}$, as shown in Figure 4. The ratios of the increased flow area of a center element modification to the center subchannel area and total flow area of a $37 \mathrm{~S}$ fuel bundle were found as $18 \%$ and $0.9 \%$, respectively.

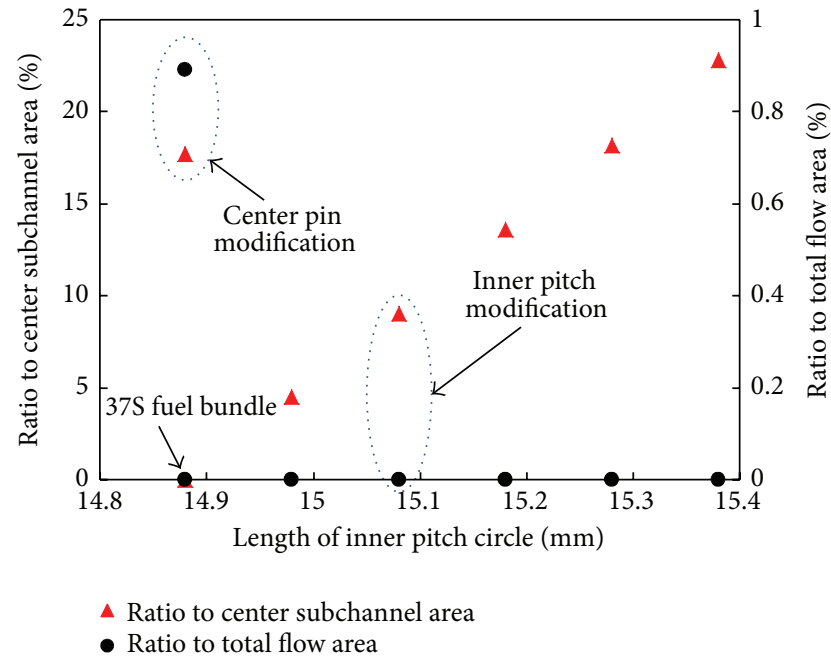

FIGURE 4: Variation of the inner subchannel area according to increasing inner pitch circles.

2.2. Modelling of AFD and RFD. A CANDU-6 core is composed of 380 fuel channels, and each fuel channel accommodates 12 fuel bundles resting horizontally. Hence, the CHF of a fuel bundle can be affected by the radial power profile (RFD) of a fuel bundle, as well as the axial power profile (AFD) in a fuel channel. Figure 5 shows the typical AFD of a $37 \mathrm{~S}$ fuel bundle in a fuel channel [7]. For a subchannel analysis of the $37 \mathrm{~S}$ fuel bundle and its pitch circle modification, the same AFD can be used because the change of the inner pitch radius does not affect the AFD. However, the power density of the 37 elements by increasing the radius of the inner pitch 
TABLE 2: Length effect of inner pitch circle on the relative power density of the fuel elements.

\begin{tabular}{lcccccc}
\hline Parameters & \multicolumn{5}{c}{ Relative power density of each pitch circle (\% change) } \\
Inner pitch circle, mm & Reference $(14.88)$ & 14.98 & 15.08 & 15.18 & 15.28 & 15.38 \\
\hline Center pitch & 0.8218 & $0.8230(0.14)$ & $0.8243(0.31)$ & $0.8258(0.49)$ & $0.8271(0.65)$ & $0.8285(0.81)$ \\
Inner pitch & 0.8538 & $0.8547(0.1)$ & $0.8552(0.16)$ & $0.8556(0.21)$ & $0.8565(0.31)$ & $0.8567(0.34)$ \\
Middle pitch & 0.9308 & $0.9305(-0.03)$ & $0.9303(-0.05)$ & $0.9302(-0.07)$ & $0.9299(-0.1)$ & $0.9298(-0.11)$ \\
Outer pitch & 1.1048 & $1.1046(-0.01)$ & $1.1045(-0.02)$ & $1.1044(-0.03)$ & $1.1043(-0.04)$ & $1.1042(-0.05)$ \\
\hline
\end{tabular}

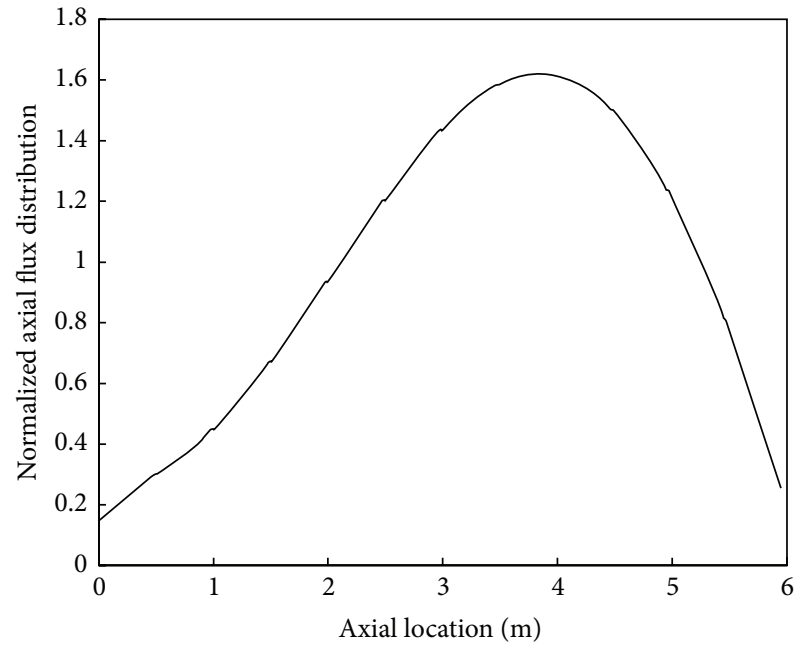

Figure 5: Normalized axial flux distribution (AFD) of a $37 \mathrm{~S}$ fuel bundle and center element modifications.

circle may be affected due to changes in the radial position of the 6 inner rods. It was examined using the WIMS code [12] for different inner pitch circles, as summarized in Table 2. It is shown that a small change of the inner pitch from 14.88 to $15.38 \mathrm{~mm}$ affected RFD negligibly. Hence, the same RFD was used for the present calculation of the inner pitch circle modification.

On the other hand, the radial power density of the 37 elements for decreasing a center element size can be changed due to small uranium materials of the center element. The normalized RFD for a center element size of $11.5 \mathrm{~mm}$ instead of the original size of $13.08 \mathrm{~mm}$ can be calculated by the averaged volume and compared to those of a $37 \mathrm{~S}$ fuel bundle, as shown in Figure 6.

\section{Subchannel Analysis}

When the twelve fuel bundles are loaded in the horizontal pressure tube, the upper section of the fuel bundle has a larger flow area than the lower section owing to gravitational force. Even if the symmetric angle of the cross-section is 180 degrees, as shown in Figure 2, this study considered a full bundle geometry for the subchannel analysis, and the total numbers of fuel rods and subchannels were 37 and 60 respectively, as shown in Figure 2. The subchannels are composed of three types, that is, triangular, square, and wall subchannels. The minimum gap between the elements of

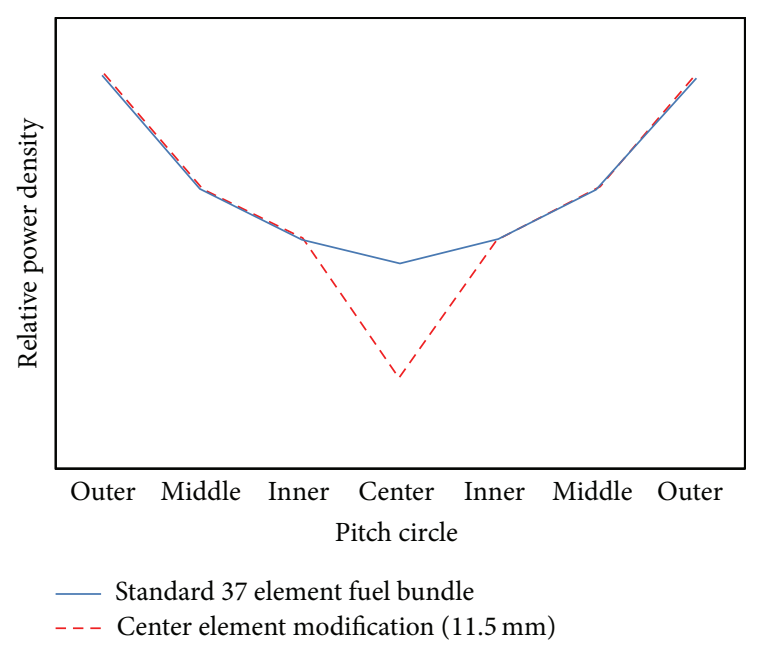

FIgURE 6: Relative power densities (RFD) of a $37 \mathrm{~S}$ fuel bundle and center element modifications.

a 37S fuel bundle was designed as $1.8 \mathrm{~mm}$. When increasing the inner pitch circle of 6 rods, the gap between the inner 6 elements and middle 12 elements can be reduced up to $1.3 \mathrm{~mm}$ in the case of the maximum outward movement, $0.5 \mathrm{~mm}$. The $1.3 \mathrm{~mm}$ minimum gap could be accepted by the Fuel Design Manual [7].

For the sensitivity studies of the effect of the inner pitch circle and small center element size on the CHF or dryout power of a fuel bundle, the subchannel analysis was performed using the ASSERT code [9], which was transferred from AECL to KAERI under a technology transfer arrangement (TCA) between KAERI/AECL. The ASSERT code is originated from the COBRA-IV computer program $[13,14]$. It has been developed to meet the specific requirements for the thermal hydraulic analysis of two-phase flow in horizontally oriented CANDU fuel bundles. In particular, it is distinguished from COBRA-IV in terms of following features [15].

(i) The lateral momentum equation is also considered with the gravity term in order to allow gravity driven lateral recirculation.

(ii) The five-equation model was applied to the twophase flow model in consideration of the thermal nonequilibrium and the relative velocity of the liquid and vapour phases. Thermal nonequilibrium is calculated from the two-fluid energy equations for 


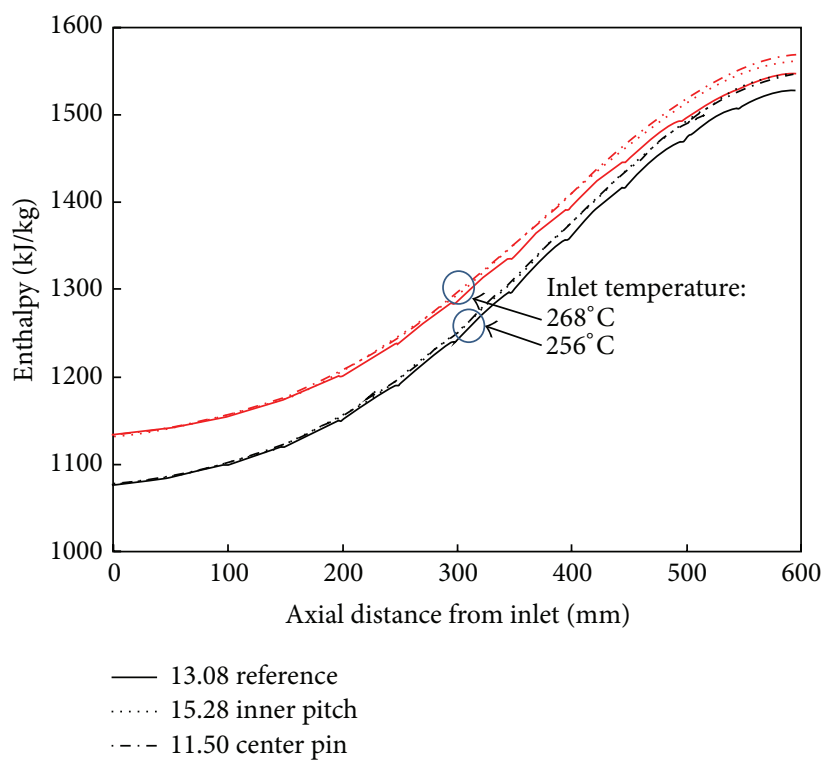

(a) Enthalpy

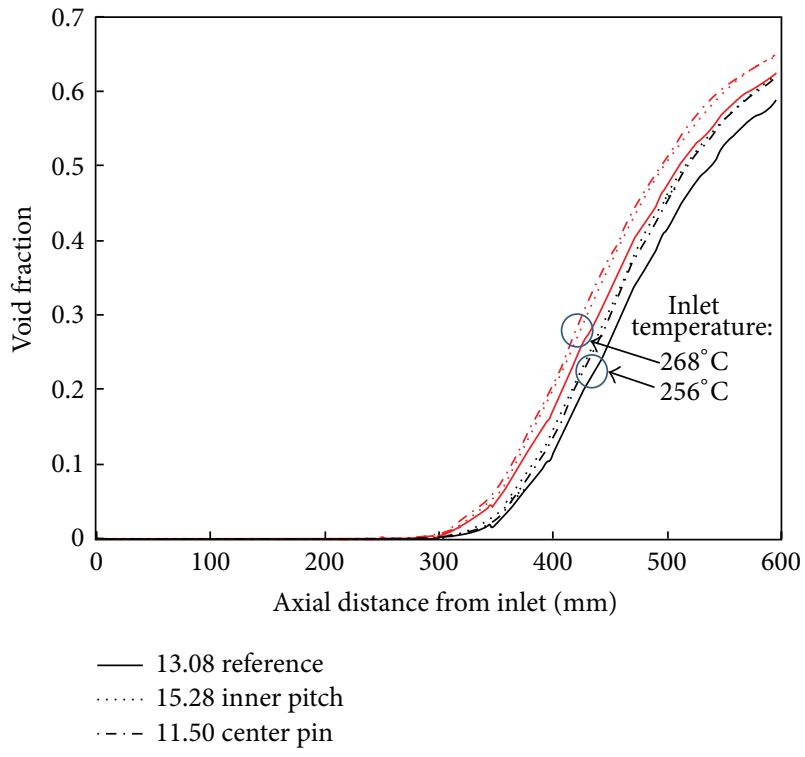

(b) Void fraction

FIGURE 7: Enthalpy and void fraction distributions of the $37 \mathrm{~S}$ fuel bundle, inner pitch, and center element modifications.

the liquid and vapour. Relative velocity is obtained from semiempirical models.

(iii) The relative velocity model accounts for the different velocities of the liquid and vapour phases in both axial and lateral directions. The lateral direction modelling contains features that consider (a) gravity driven phase separation or buoyancy drift in horizontal flow, (b) void diffusion turbulent mixing, and (c) void drift (void diffusion to a preferred distribution) as well.

To find the subchannel and axial locations of the first CHF occurrence in a fuel channel, the calculation will continue until the convergence tolerance is reached at the specified criteria, "ODVTOL" in the ASSERT code. Once the first CHF for the given mass flow and inlet temperature has occurred at any subchannel and axial location during iteration, the calculation is stopped and all flow parameters are printed out. Onset-of-dry-out iteration for the first CHF occurrence can be found as follows:

$$
\mathrm{MCHFLO} \leq \mathrm{MCHFR} \leq \mathrm{MCHFUP},
$$

where "MCHFLO" and "MCHFUP" are the lower and upper bounds, respectively, for the target minimum CHFR (MCHFR), and "MCHFR" is the minimum CHF ratio and is defined as

$$
\operatorname{MCHFR}=\min \left(\frac{q_{c r}^{\prime}}{q^{\prime}}\right),
$$

where $q_{c r}^{\prime}$ is the CHF and $q^{\prime}$ is the zonal heat flux. "ODVTOL" is the relative convergence tolerance on the iteration parameter, which is defined as follows:

$$
\left|\frac{\Psi_{n}-\Psi_{n-1}}{\Psi_{n-1}}\right| \leq \text { ODVTOL, }
$$

where $\Psi$ is the iteration parameter and $n$ is the iteration number. $\Psi$ and $n$ are given as 1.00004 and 20, respectively, for the present calculation.

\section{Results and Discussion}

Subchannel analyses were performed for the modifications of the inner pitch circle and center element size of a $37 \mathrm{~S}$ fuel bundle using the ASSERT code with a CHF lookup table [16]. To examine the dry-out power enhancement for the present calculation, the inlet temperatures were selected as $256^{\circ} \mathrm{C}, 262^{\circ} \mathrm{C}$, and $268^{\circ} \mathrm{C}$, and the inlet mass flow is selected as $20 \mathrm{~kg} / \mathrm{s}, 24 \mathrm{~kg} / \mathrm{s}$, and $30 \mathrm{~kg} / \mathrm{s}$. The inner pitch circle of a $37 \mathrm{~S}$ fuel bundle is selected as $15.28 \mathrm{~mm}$, which gave almost the same flow area of the center subchannel as that of a center element diameter of $11.5 \mathrm{~mm}$, as shown in Figure 4.

4.1. Axial Enthalpy and Void Fraction. The bundle averaged enthalpies for the $37 \mathrm{~S}$ fuel bundle and those modifications were calculated at each axial location from the channel entrance. As shown in Figure 7(a), it is shown that the bundle averaged enthalpies are increasing as the coolant flows downstream. The axial enthalpy distributions for a $37 \mathrm{~S}$ fuel bundle and those modifications have similar trends but the enthalpy rise for the modifications is higher than that of a $37 \mathrm{~S}$ fuel bundle owing to increasing dry-out power of the modifications. The axial void fraction distribution has the same trend as the enthalpy distribution, as shown in Figure 7(b), and the void formations for three types of calculations are starting almost at the same axial location or the middle of the fuel channel.

4.2. Subchannel Enthalpy. Figure 8 shows a comparison of the subchannel enthalpy distributions of a $37 \mathrm{~S}$ fuel bundle 


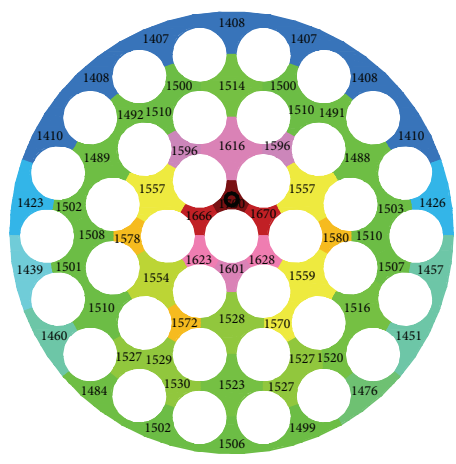

CHF subchannel loc. (O): 1 CHF axial loc. (cm): 516.27 $\mathrm{CHF}\left(\mathrm{MW} / \mathrm{m}^{2}\right): 0.95172$ Enthalpy (56t20g14.88)

(a) $37 \mathrm{~S}$ fuel bundle

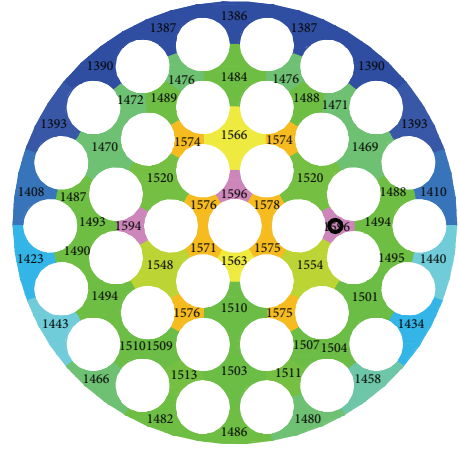

CHF subchannel loc. (O): 10 CHF axial loc. $(\mathrm{cm}): 474.73$ $\mathrm{CHF}\left(\mathrm{MW} / \mathrm{m}^{2}\right): 1.37888$ Enthalpy (56t $20 \mathrm{~g}$ inner pitch)

(b) Inner pitch modification

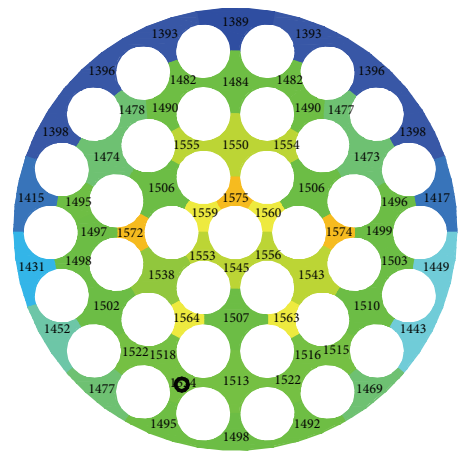

CHF subchannel loc. (O): 32 CHF axial loc. $(\mathrm{cm}): 481.69$ $\mathrm{CHF}\left(\mathrm{MW} / \mathrm{m}^{2}\right): 1.58558$

Enthalpy (56t $20 \mathrm{~g}$ center pin)

(c) Center element modification

Figure 8: Enthalpy distributions of the standard 37-element fuel and its modifications for $256^{\circ} \mathrm{C}$.

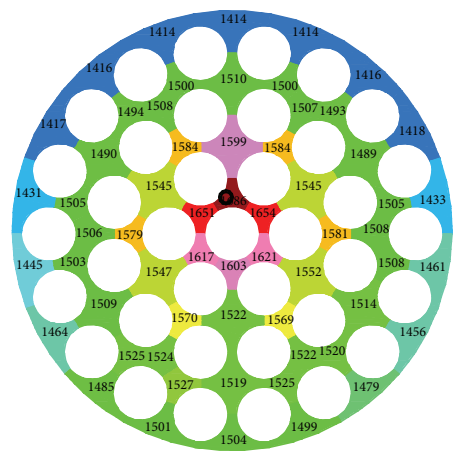

CHF subchannel loc. (O): 1 CHF axial loc. $(\mathrm{cm}): 490.62$ CHF $\left(\mathrm{MW} / \mathrm{m}^{2}\right): 1.02476$ Enthalpy (68t20g14.88)

(a) $37 \mathrm{~S}$ fuel bundle

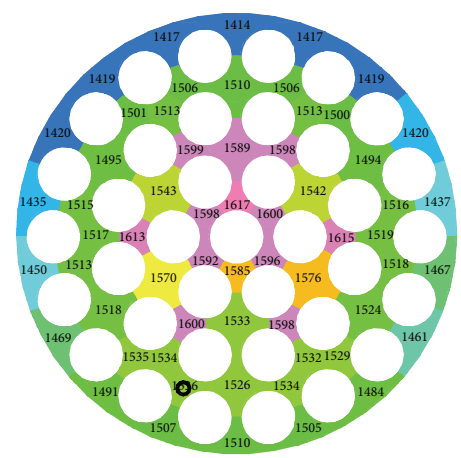

CHF subchannel loc. (O): 32 CHF axial loc. $(\mathrm{cm}): 474.73$ $\mathrm{CHF}\left(\mathrm{MW} / \mathrm{m}^{2}\right): 1.50815$ Enthalpy (68t $20 \mathrm{~g}$ inner pitch)

(b) Inner pitch modification

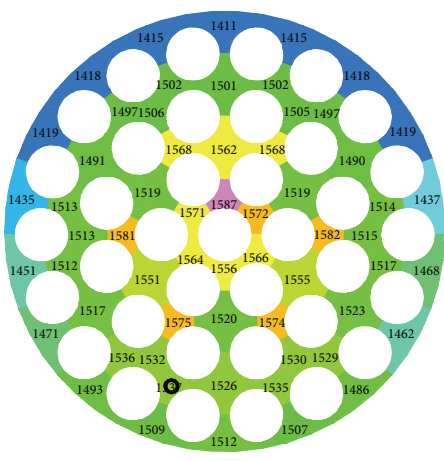

CHF subchannel loc. (O): 32 CHF axial loc. (cm): 474.73 CHF $\left(\mathrm{MW} / \mathrm{m}^{2}\right): 1.49609$ Enthalpy (68t $20 \mathrm{~g}$ center pin)

(c) Center element modification

Figure 9: Enthalpy distributions of the standard 37-element fuel and its modifications for $268^{\circ} \mathrm{C}$.

and its modifications for an inlet temperature of $256^{\circ} \mathrm{C}$. Since the enthalpies of the center subchannel numbers 1 through 6 for a $37 \mathrm{~S}$ fuel bundle are much higher than those of other subchannels for the inlet temperature of $256^{\circ} \mathrm{C}$, as expected, the first $\mathrm{CHF}$ occurrence of a $37 \mathrm{~S}$ fuel bundle was found at subchannel number 1, as shown in Figure 8(a), while those of the inner pitch and center element modifications were found at subchannel numbers 10 and 32, respectively, as shown in Figures 8(b) and 8(c). It was noted that the large flow area of the center subchannels makes the subchannel enthalpy distribution more uniform than that of a $37 \mathrm{~S}$ fuel bundle. In addition, the first CHF for the inner pitch and center element modifications was moved from the center subchannel to the inner and outer subchannels, respectively. When compared with the subchannel enthalpies of two modifications, the center subchannel enthalpies for a small center element are lower than those of the large inner pitch because the small center element has a low power density, as shown in Figure 6. Additionally, the inner subchannel enthalpies of the large inner pitch were higher than those of the small center element, as shown in Figures $8(\mathrm{~b})$ and $8(\mathrm{c})$. This caused the flow area of the inner subchannels to be reduced by enlarging the inner pitch, even when the flow areas of the center subchannels of two modifications were the same.

On the other hand, Figure 9 shows a comparison of the subchannel enthalpy distributions of a $37 \mathrm{~S}$ fuel bundle and its modifications for an inlet temperature of $268^{\circ} \mathrm{C}$. The subchannel enthalpy distributions of the modifications as shown in Figure 9 were similar to those for the inlet temperature of $256^{\circ} \mathrm{C}$, except that the first $\mathrm{CHF}$ location of the large inner pitch was moved from inner subchannel number 11 for the inlet temperature of $256^{\circ} \mathrm{C}$ to outer subchannel number 32 for the inlet temperature of $268^{\circ} \mathrm{C}$. It was noted that the subchannel enthalpy distribution and the first $\mathrm{CHF}$ 


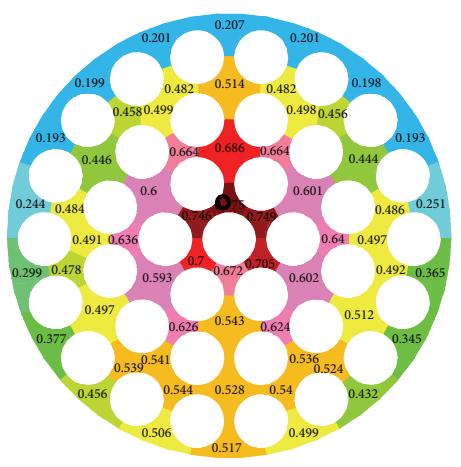

CHF subchannel loc. (O): 1 CHF axial loc. (cm): 516.27 $\mathrm{CHF}\left(\mathrm{MW} / \mathrm{m}^{2}\right): 0.95172$ Void fraction $(56 t 20 g 14.88)$ (a) $37 \mathrm{~S}$ fuel bundle

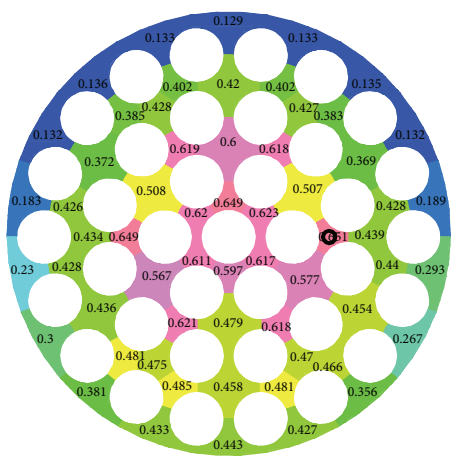

CHF subchannel loc. (O): 10 CHF axial loc. (cm): 474.73 CHF (MW/m²): 1.37888 Void fraction (56t $20 \mathrm{~g}$ inner pitch) (b) Inner pitch modification

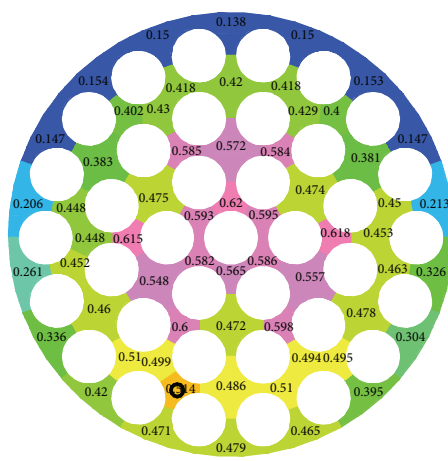

CHF subchannel loc. (O): 32 CHF axial loc. $(\mathrm{cm}): 481.69$ $\mathrm{CHF}\left(\mathrm{MW} / \mathrm{m}^{2}\right): 1.58558$ Void fraction $(56 t 20 \mathrm{~g}$ center pin)

(c) Center element modification

FIGURE 10: Void fraction distributions of the standard 37-element fuel and its modifications at $256^{\circ} \mathrm{C}$.

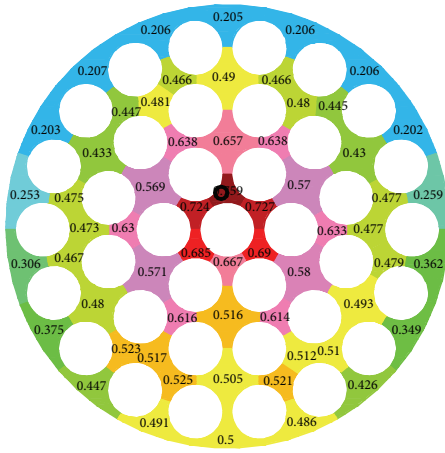

CHF subchannel loc. (O): 1 CHF axial loc. (cm): 490.62 CHF (MW/m²): 1.02476 Void fraction $(68 t 20 \mathrm{~g} 14.88)$ (a) $37 \mathrm{~S}$ fuel bundle

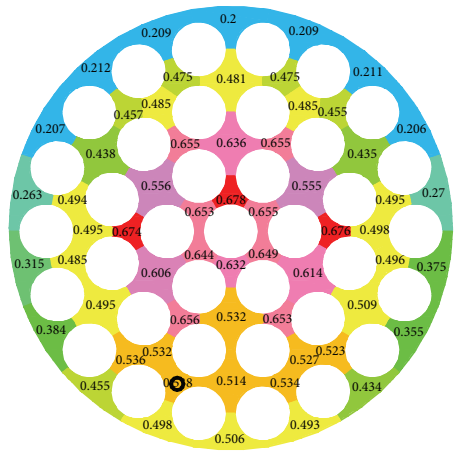

CHF subchannel loc. (O): 32 CHF axial loc. (cm): 474.73 CHF (MW/m²): 1.50815 Void fraction (68t $20 \mathrm{~g}$ inner pitch) (b) Inner pitch modification

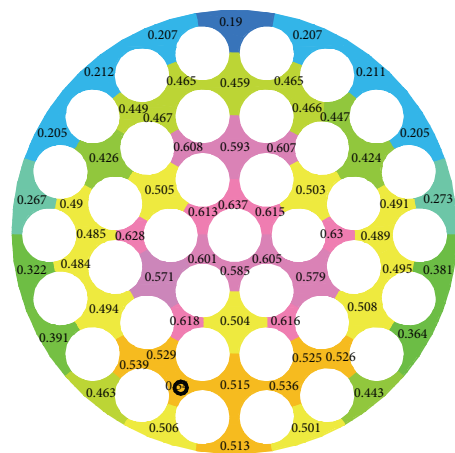

CHF subchannel loc. (O): 32 CHF axial loc. (cm): 474.73 CHF (MW/m²): 1.49609 Void fraction $(68 t 20 \mathrm{~g}$ center pin)

(c) Center element modification

FIGURE 11: Void fraction distributions of the standard 37-element fuel and its modifications at $268^{\circ} \mathrm{C}$.

occurrences for the case of the high inlet temperature of $268^{\circ} \mathrm{C}$ can be affected by mixing the characteristics among the subchannels as well as the inlet temperature.

4.3. Subchannel Void Fraction. Figures 10 and 11 show the void fraction distributions of a $37 \mathrm{~S}$ fuel bundle and those modifications at the location of the first CHF occurrence for $256^{\circ} \mathrm{C}$ and $268^{\circ} \mathrm{C}$ inlet temperatures, respectively. The void fraction distributions of the modifications are more uniform than those of a $37 \mathrm{~S}$ fuel bundle, as shown in Figure 10. The location of the first $\mathrm{CHF}$ occurrence of a $37 \mathrm{~S}$ fuel bundle was moved from subchannel number 1 to number 10 and number 33 for the inner pitch and center element modifications, respectively. It was noted that the enthalpies or void fractions of the inner subchannels are more prone to have the $\mathrm{CHF}$ occur firstly as they are closer by increasing the inner pitch. The axial CHF location of a $37 \mathrm{~S}$ fuel bundle was $508.48 \mathrm{~cm}$, or at the axial 10th bundle from the channel inlet, while that of the inner pitch and center element modifications was $478.82 \mathrm{~cm}$ and $481.69 \mathrm{~cm}$, respectively, or at the 9th axial bundle.

4.4. Dry-Out Power Enhancement. Dry-out powers of the inner pitch and center element modifications under each mass flow and inlet temperature were investigated and compared to those of a $37 \mathrm{~S}$ fuel bundle. To investigate the enhancement of dry-out power of its modifications in terms of a 37S fuel bundle, the dry-out power enhancement ratio is defined as the ratio of dry-out power of its modification to that of a $37 \mathrm{~S}$ fuel bundle. Figure 12 shows the dry-out power enhancement of the modifications for each mass flow and inlet temperature conditions. It was shown that the dry-out powers of the modifications are always higher than those of a $37 \mathrm{~S}$ fuel bundle for all mass and inlet temperature conditions. These results agree well with references 8 and 10. In addition, most dry-out powers of the small center element are higher 


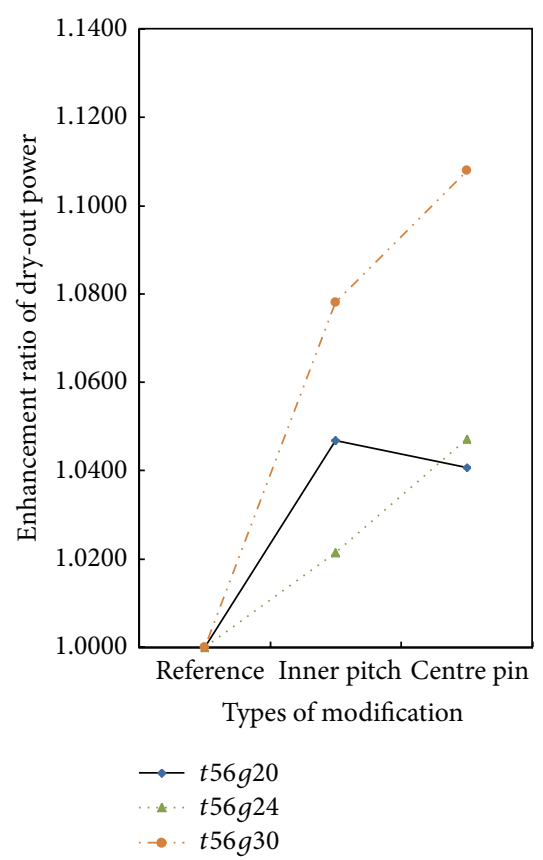

(a) Inlet temperature, $256^{\circ} \mathrm{C}$

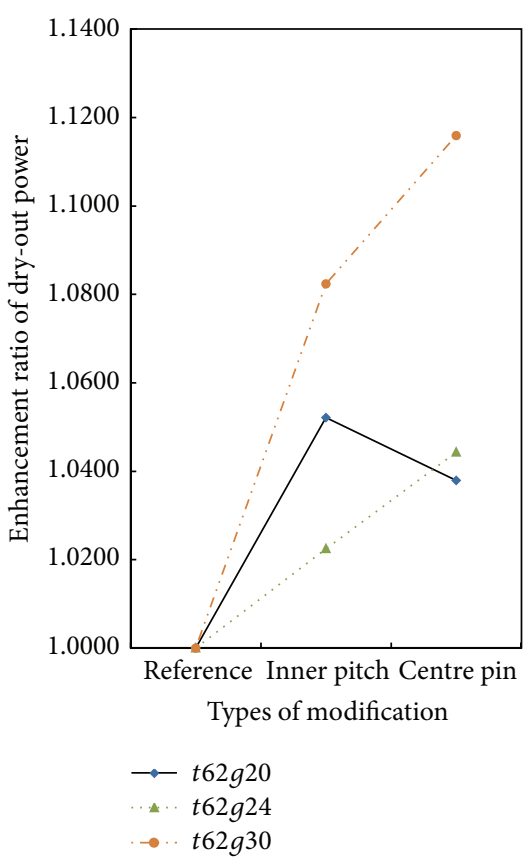

(b) Inlet temperature, $262^{\circ} \mathrm{C}$

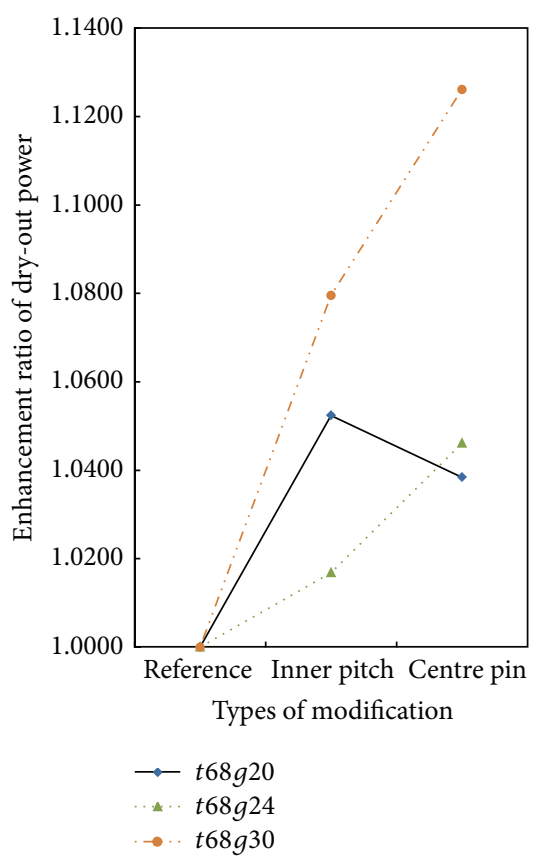

(c) Inlet temperature, $268^{\circ} \mathrm{C}$

FIGURE 12: Comparison of dry-out enhancements of inner pitch and center element modificationsin terms of a $37 \mathrm{~S}$ fuel bundle.

than those of the large inner pitch except for the low mass flow condition of $20 \mathrm{~kg} / \mathrm{s}$. It was noted that the turbulent intensity and mixing characteristics among the subchannels of the small center element may be different from those of the large inner pitch and can be affected by the low power density and small heated area of the center element, as shown in Figure 6.

While considering the dry-out power enhancement for a mass flow of $20 \mathrm{~kg} / \mathrm{s}$, that of the large inner pitch is higher compared to that of the small center element and this trend becomes significant as the inlet temperature increases. However, for high mass flows, the dry-out power enhancement of the small center element is higher than that of the large inner pitch. It is noted that the higher dry-out power enhancement of the center element modification should be caused by the power density reduction of a center element, as well as the large flow area of the center subchannels.

Even if the small center element resulted in a higher dryout power enhancement and might be more effective in terms of the dry-out power enhancement, the adverse impact on the safety and fuel management cost for its modification should be considered.

4.5. Void Fraction Imbalance Factor. In this section, the void fraction distribution or nonuniformity of the subchannel void fraction was selected to investigate its correlation with the dry-out power enhancement ratio. Also, the comparison of the correlation between the nonuniformity of the subchannel void fraction at the CHF locations and dry-out power enhancement ratios for the fuel bundle modifications was made under the same inlet flow conditions because the dryout power enhancement ratio is not the local properties such as $\mathrm{CHF}$ and quality.

To investigate the correlation between the local void fraction at the first CHF location and the dry-out power enhancement ratio, the dry-out power enhancement ratio and the local void fraction at the axial and subchannel locations corresponding to the first CHF occurrence were plotted together for each flow condition, as shown in Figure 13. The void fraction imbalance factor is defined as a local subchannel void fraction divided by a section averaged void fraction at the location of the first CHF occurrence. This shows that the dry-out power enhancement ratio of the center element modification is lower than that of the inner pitch modification (see "t262g20" and "t268g20" in Figure 13) if the void fraction imbalance factor of the center element modification is higher than that of the inner pitch modification. It was noted that the dry-out power of a fuel bundle would be higher when the local void fraction imbalance factor at the location of the first CHF occurrence is lower.

\section{Conclusion}

The subchannel analyses were performed to investigate the enthalpy distribution, void fraction distribution, and dryout power enhancement of the fuel bundle modifications of a $37 \mathrm{~S}$ fuel bundle. Two approaches such as the increase of the inner pitch circle and the decrease of the center element diameter to enlarge the flow area of the center subchannels were considered to enhance the dry-out power of an existing CANDU fuel bundle. The uncertainty of the dry-out power 


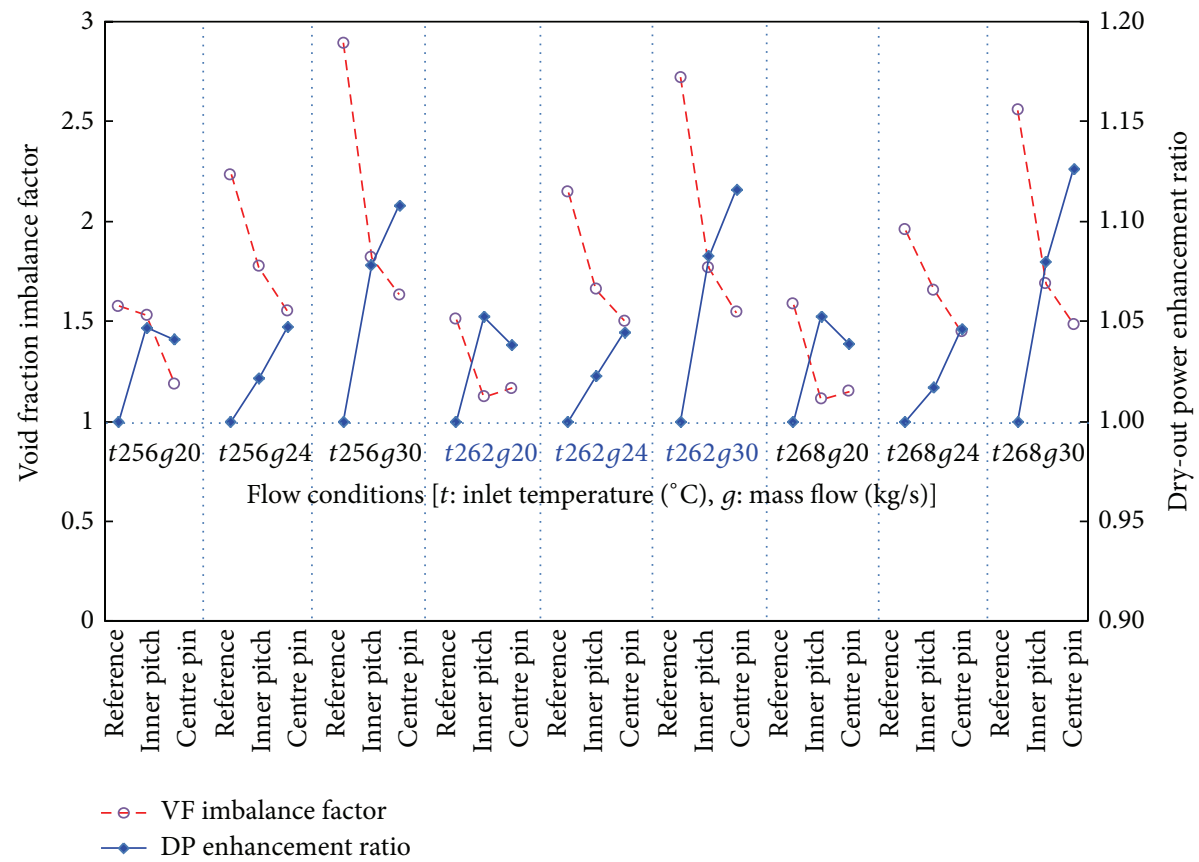

FIGURE 13: Comparison of void fraction imbalance factors and dry-out power enhancement ratioaccording to the flow conditions.

could be existed for a $37 \mathrm{~S}$ fuel bundle and its modifications, but it was not considered because of the sensitivity studies for a $37 \mathrm{~S}$ fuel bundle and its modifications. From the present study, the following were concluded.

The subchannel enthalpy and void fraction of a $37 \mathrm{~S}$ fuel bundle modification were redistributed as expected when the flow area of the center subchannels are enlarged by increasing the inner pitch circle or reducing the center element diameter. In addition, the subchannel locations of the first CHF occurrence of those modifications were moved to the other subchannels such as the middle subchannel or outer subchannel. In addition, the axial locations of the first $\mathrm{CHF}$ occurrence were moved from the 10th fuel bundle to the 9th fuel bundle according to the modifications. Finally, the dry-out powers of the two types of modification of a $37 \mathrm{~S}$ fuel bundle could be enhanced. In addition, two approaches to enlarging the center subchannel area were revealed as very effective ways to increase the dry-out power of a CANDU fuel bundle or to overcome the power deration owing to an aging CANDU power plant.

While considering the dry-out power enhancement for a mass flow of $20 \mathrm{~kg} / \mathrm{s}$, that of the large inner pitch is higher compared to that of the small center element and this trend became significant as the inlet temperature increases. However, for high mass flows, dry-out power enhancements of the small center element are higher than those of the large inner pitch. It was noted that the enthalpy and void fraction distribution of the large inner pitch are different from those of the small center element and should be caused by the power density reduction of a center element, as well as the large flow area of the center subchannels.

\section{Conflict of Interests}

The authors declare that there is no conflict of interests regarding the publication of this paper.

\section{Acknowledgment}

This work was supported by the National Research Foundation of Korea (NRF) grant funded by the Korea government (Ministry of Science, ICT, and Future Planning) (no. NRF2012M2A8A4025960).

\section{References}

[1] D. C. Groeneveld and K. C. Goel, "A method of increasing critical heat flux in nuclear fuel bundles," CRNL-1763, 1978.

[2] A. G. McDonald and S. C. Sutradhar, "CANFLEX bundle thermalhydraulic experiments: part 4, Freon CHF tests on the 37Ehybrid bundle, equipped with two space planes and four bearing pad planes," HPBP-32/ARD-TD-124, 1988.

[3] D. C. Groeneveld, "On the definition of critical heat flux margin," Nuclear Engineering and Design, vol. 163, no. 1-2, pp. 245-247, 1996.

[4] G. C. Dimmick, W. W. R. Inch, J. S. Jun et al., "Full scale water CHF testing of the CANFLEX bundle," in Proceedings of the 6th International Conference on CANDU Fuel, pp. 103-113, Ontario, Canada, 1999.

[5] L. K. H. Leung, J. S. Jun, G. R. Dimmick, D. E. Bullock, W. W. R. Inch, and H. C. Suk, "Dryout power of a CANFLEX bundle string with raised bearing pads," in Proceeding of the 7th International Conference on CANDU Fuel, pp. 27-40, Kingston, Ontario, Canada, 2001. 
[6] L. K. H. Leung and F. C. Dimayuga, "Measurements of critical heat flux in CANDU 37-element bundle with a steep variation in radial power profile," Nuclear Engineering and Design, vol. 240, no. 2, pp. 290-298, 2010.

[7] Fuel Design Manual for CANDU-6 Reactors, DM-XX-37000001, AECL, 1989.

[8] J. H. Bae and J. H. Park, "The effect of a CANDU fuel bundle geometry variation on thermalhydraulic performance," Annals of Nuclear Energy, vol. 38, no. 9, pp. 1891-1899, 2011.

[9] M. B. Carver, J. C. Kiteley, R. Q.-N. Zhou, S. V. Junop, and D. S. Rowe, "Validation of the assert subchannel code: prediction of critical heat flux in standard and nonstandard CANDU bundle geometries," Nuclear Technology, vol. 112, no. 3, pp. 299-314, 1995.

[10] J. H. Park and Y. M. Song, "The effect of inner ring modification of standard 37-element fuel on CHF enhancement," Annals of Nuclear Energy, vol. 70, pp. 135-140, 2014.

[11] A. Tahir, Y. Parlatan, M. Kwee, W. Liauw, G. Hadaller, and R. Fortman, "Modified 37-element bundle dryout," in Proceedings of the 14th International Topical Meeting on Nuclear Reactor Thermal Hydraulics (NURETH '11), Toronto, Canada, 2011.

[12] S. R. Douglas, "WIMS-AECL release 2-5d users manual," COG94-52(Rev. 4), FFC-RRP-299, AECL, 2000.

[13] C. L. Wheeler, C. W. Stewart, R. J. Cena et al., "COBRA-IV-I: an interim version of COBRA for thermal-hydraulic analysis of rod-bundle nuclear fuel elements and cores," Battelle Pacific Northwest Laboratories Report BNWL-1962, Battelle Pacific Northwest Laboratories, 1976.

[14] C. W. Stewart, C. L. Wheeler, R. J. Cena, C. A. McMonagle, J. M. Cuta, and D. S. Trent, "COBRA-IV: the model and the method," Battelle Pacific Northwest Laboratories Report BNWL-2214, 1977.

[15] Y. F. Rao, Z. Cheng, G. M. Waddington, and A. Nava-Dominguez, "ASSERT-PV 3.2: advanced subchannel thermalhydraulics code for CANDU fuel bundles," Nuclear Engineering and Design, vol. 275, pp. 69-79, 2014.

[16] D. C. Groeneveld, L. K. H. Leung, P. L. Kirillov et al., "The 1995 look-up table for critical heat flux in tubes," Nuclear Engineering and Design, vol. 163, no. 1-2, pp. 1-23, 1996. 


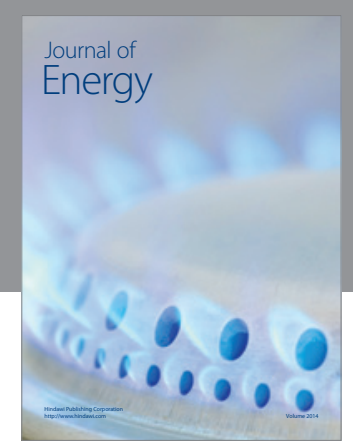

Journal of

Industrial Engineering
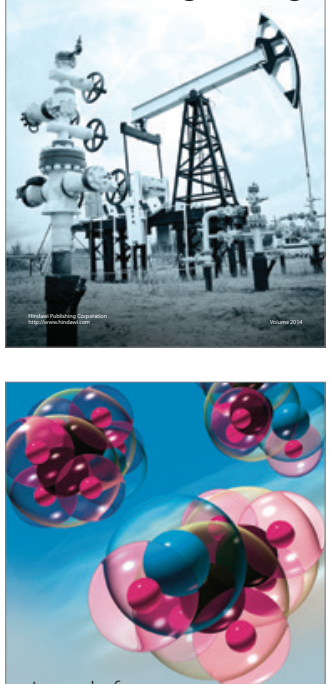

Fuels
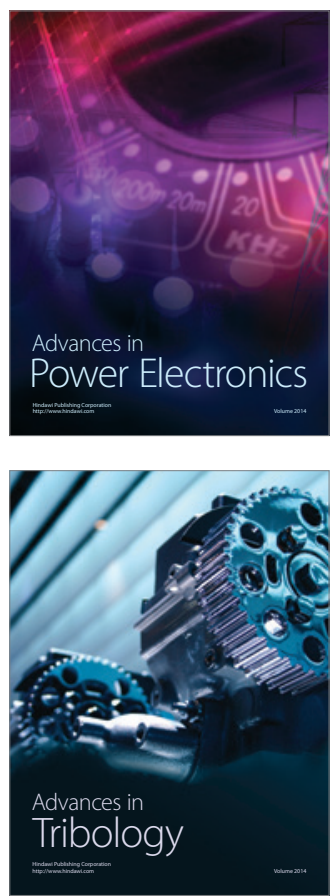

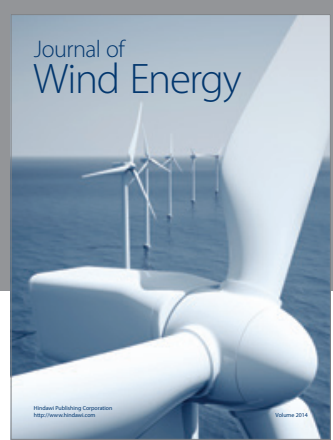

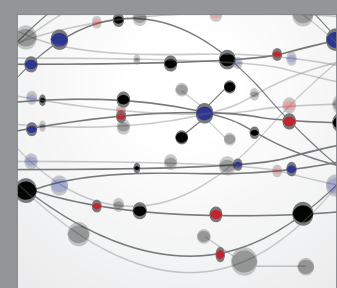

The Scientific World Journal

Submit your manuscripts at http://www.hindawi.com

Journal of

Structures
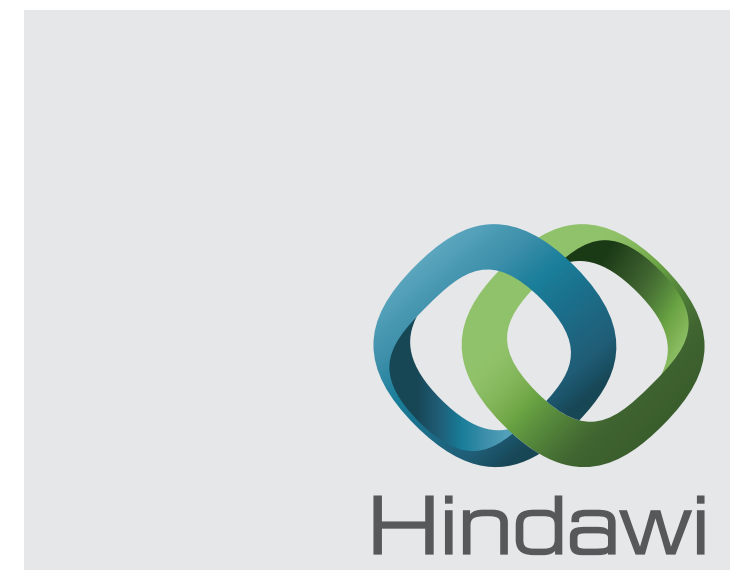

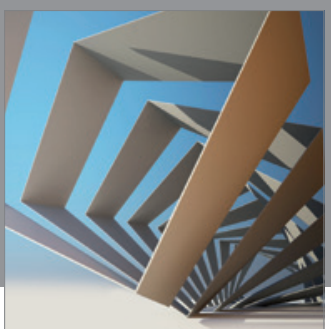

Rotating

Machinery
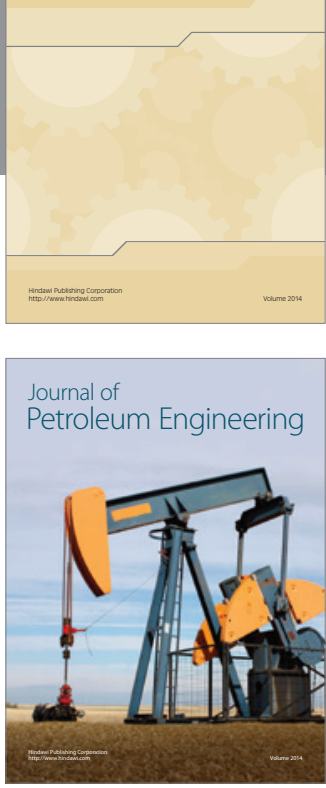

Journal of

Solar Energy
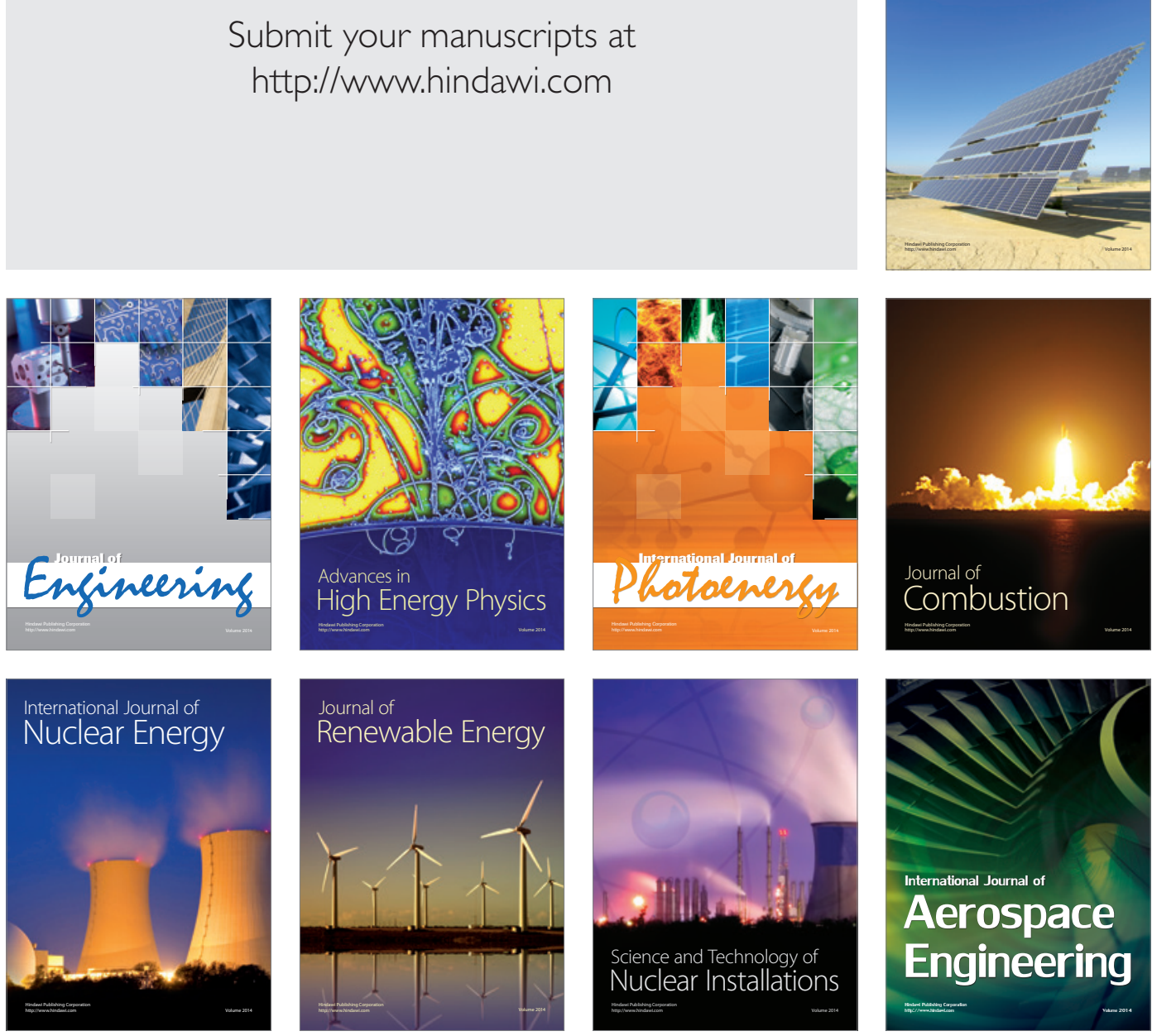